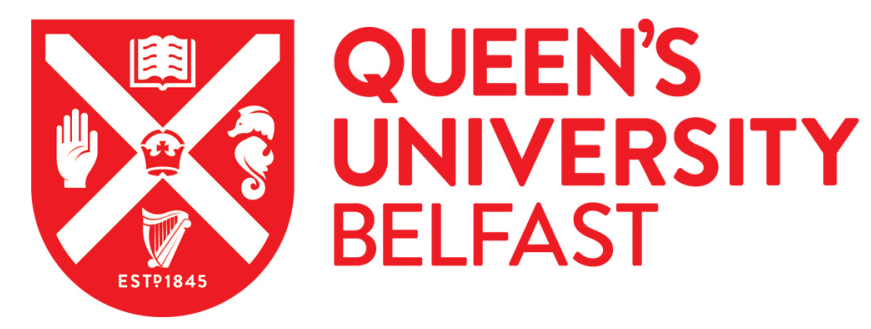

\title{
Promoting Osseointegration of Ti Implants through Micro/Nanoscaled Hierarchical Ti Phosphate/Ti Oxide Hybrid Coating
}

Jiang, N., Guo, Z., Sun, D., Li, Y., Yang, Y., Chen, C., Zhang, L., \& Zhu, S. (2018). Promoting Osseointegration of Ti Implants through Micro/Nanoscaled Hierarchical Ti Phosphate/Ti Oxide Hybrid Coating. ACS Nano, 12(8), 1-9. https://doi.org/10.1021/acsnano.8b02227

\section{Published in:}

ACS Nano

\section{Document Version:}

Peer reviewed version

Queen's University Belfast - Research Portal:

Link to publication record in Queen's University Belfast Research Portal

\section{Publisher rights}

(C2018 American Chemical Society. This work is made available online in accordance with the publisher's policies. Please refer to any applicable terms of use of the publisher.

\section{General rights}

Copyright for the publications made accessible via the Queen's University Belfast Research Portal is retained by the author(s) and / or other copyright owners and it is a condition of accessing these publications that users recognise and abide by the legal requirements associated with these rights.

\section{Take down policy}

The Research Portal is Queen's institutional repository that provides access to Queen's research output. Every effort has been made to ensure that content in the Research Portal does not infringe any person's rights, or applicable UK laws. If you discover content in the Research Portal that you believe breaches copyright or violates any law, please contact openaccess@qub.ac.uk. 


\title{
Promoting Osseointegration of Ti Implants through Micro/nano-scaled Hierarchical Ti Phosphate / Ti Oxide Hybrid Coating
}

Nan Jiang ${ }^{\dagger 1}$, Zhijun Guo ${ }^{\dagger 2,3}$, Dan $\mathrm{Sun}^{3}$, Yubao $\mathrm{Li}^{2}$, Yutao Yang ${ }^{1}$, Chen $\mathrm{Chen}^{2}$, Li Zhang $^{* 2}$ and Songsong $\mathrm{Zhu}^{* 1}$

1. State Key Laboratory of Oral Diseases, \& National Clinical Research Center for Oral Disease, \& West China Hospital of Stomatology, Sichuan University, Chengdu, China

2. Research Center for Nano-Biomaterials, Analytical \& Testing Center, Sichuan University, Chengdu, China

3. School of Mechanical \& Aerospace Engineering, Queens University Belfast, Belfast, UK

\begin{abstract}
In this study, micro/nano-scaled hierarchical hybrid coatings containing titanium (Ti) phosphate and $\mathrm{Ti}$ oxide have been fabricated with the aim of promoting osseointegration of Ti-based implants. Three representative surface coatings, namely, micro/nano-grass Ti (P-G-Ti), micro/nano-clump Ti, (P-C-Ti) and micro/nano-rod Ti (P-R-Ti) have been produced. In-depth investigation into the coating surface morphology, topography, chemical composition, as well as the surface /cell interaction have been carried out using scanning electron microscopy (SEM), transmission electron microscope (TEM), X-ray photoelectron spectroscopy (XPS), X-ray diffraction (XRD), contact-angle measurement, and protein adsorption assay. In addition, in vitro performance of the coating (cell proliferation, adhesion and differentiation) has been evaluated using rat bone marrow stromal cells (BMSCs) and in vivo assessments have been carried out based on rats tibia implantation model.
\end{abstract}

All the hybrid coating modified implants demonstrated enhanced protein adsorption and BMSC viability, adhesion and differentiation, with P-G-Ti showing the best 
bioactivity amongst all samples. Subsequent in vivo osseointegration tests confirmed that P-G-Ti has induced a much stronger interfacial bonding with the host tissue, indicated by the twofold increase in the ultimate shear strength and over six fold increase in the maximum push-out force comparing to un-modified Ti implants. The state-of-the-art coating technology proposed for Ti-based implants in this study holds great potential in advancing medical devices for the next generation healthcare technology.

Keywords: Ti phosphate; Ti oxide; osseointegration; micro/nano scale surface morphology; hierarchical structure;

The rapid advancement of modern technology and world economy have led to significantly improved quality of life for the world population in the past few decades. Nowadays, people are having a much longer life expectancy, and it is expected that people > 65 years will reach $21.1 \%$ by the end of $2050 .{ }^{1}$ The increasing aging population has also led to a greater demand for hard tissue implants (bone and dental, in particular), as elderlies are more prone to severe musculoskeletal diseases and dental problems..$^{2-4}$ On the other hand, the demand for hard tissue implants by younger patients ( $<65$ years) cannot be underestimated, taking into account the incidence of accidents, diseases and the increasing demand in cosmetic surgeries.

Ti-based implants have been widely used in orthopedics and dental surgery due to their excellent mechanical properties, chemical stability and biocompatibility. ${ }^{5-8}$ Typical Ti-based orthopedic and dental implants are expected to serve over ten years, ${ }^{9}$ however, the lack of initial osseointegration due to the materials bio-inertness often leads to implant failures. For instance, according to the National Joint Registry hip Annual Report Data 2009, about 10\% total procedures required revision for England and Wales alone, and aseptic loosening accounted for $49 \%$ of the revision procedures. ${ }^{10,11}$ Such high failure rate would inevitably lead to increased risk of infection/ complications, hospital costs and last but not least, severely affecting the patients' quality of life. ${ }^{12-14}$ 
In order to address these challenges, researchers have explored various approaches to modify the Ti surface structure/chemistry while retaining its excellent bulk properties in order to increase the surgery success rate and prolong the life span of the implants. As such, advanced coatings are often applied to Ti based implants to improve their osteoconductivity and osseointegration. ${ }^{15-17}$ Natural trabecular bones are mainly composed of calcium (Ca) and phosphorous (P) and have a micro/nano-scaled hierarchical structure. ${ }^{18-21}$ The creation of bio-mimic implant coatings simulating the composition/structure of the natural bones has been the subject of intensive research in the past few decades, and the coatings developed mostly contains hydroxyapatite (HA) and/or calcium phosphate $(\mathrm{CaP}) .{ }^{22-25}$ Recently, studies focusing on controlling/tailoring the Ti implant surface roughness also attracted much attention. While Ti with microscale surface roughness is shown to enhance the osteoblastic differentiation of osteoblast lineage cells, ${ }^{26-28}$ some researchers also suggested that the microscale-texture alone may inhibit the cell proliferation, ${ }^{29}$ a hierarchical micro-nano scaled Ti surface mimicking the microstructure of the natural trabecular bone is more ideal for bone growth. ${ }^{30}$ As a result, a wide range of "intelligent" materials systems with complex hierarchical organization of surface structures have also been explored, with the aim of mimicking the biofunctions of natural bone tissues. ${ }^{31}$ Yin et al. obtained a micro/nanoscale hierarchical structure on Ti surface via electrochemical etching technique and greater MG63 cell adhesion and attachment have been achieved when comparing to the sand blasted and machined $\mathrm{Ti}$ surfaces. ${ }^{32}$ Lin et al., produced $\mathrm{TiO}_{2}$ nanotubes, nanosponge (both through electrochemical anodization), and nano/micro nest-liked $\mathrm{TiO}_{2}$ (through hydrothermal alkaline treatment). The comparative studies in vivo showed that the nano/micro nest-liked $\mathrm{TiO}_{2}$ demonstrated the best bone-implant integration amongst all samples. ${ }^{33}$

Despite the effort in the field, studies in relation to $\mathrm{P}$ incorporated Ti with 3D hierarchical surface structures has been less explored. Sul ${ }^{34}$ through electrochemical micro-arc oxidation, successfully incorporated $\mathrm{P}$ anions into flat $\mathrm{TiO}_{2}$ coatings (pore sizes 1.3-1.5 $\mu \mathrm{m}$ ). Stronger bone tissue reactions have been reported but no details have been given in relation to the cell work. Park et al., produced a crystalline P-incorporated 
Ti oxide surface deploying hydrothermal treatment using phosphoric acid. The surface exhibited microscale roughness and showed improved wettability and enhanced MC3T4-E1 cell attachment, vitality, and osteoblastic gene expression. ${ }^{25,}{ }^{35}$ Recently, Yada et al., through hydrothermal treatment, produced 3D micro-and nano-structured Ti phosphates with varied surface morphology and chemical compositions. These surfaces exhibited tunable wettability and have been successfully demonstrated for photocatalytic applications. ${ }^{36}$

In this work, micro-nanoscaled hierarchical Ti phosphate / Ti oxide hybrid coatings have been produced for Ti implants with the aim of promoting their osseointegration. A modified hydrothermal and pressure method has been deployed to create tailored surface topography and chemistry for our hybrid coatings and the performance of the modified implants have been evaluated both in vitro and in vivo.

\section{Results and discussion}

\section{Hyrbid coating formation mechanism and surface characterization}

Classically, crystallization starts from cluster formation with primary building blocks and the subsequent crystal growth proceeds via an ion-by-ion attachment process. Spontaneous crystal coarsening takes place through diffusion of constituent ions from the surrounding solution or by consumption of small particles. ${ }^{37}$ The formation of Tiphosphate with various surface morphology is the result of the reaction between $\mathrm{Ti}$, $\mathrm{H}_{2} \mathrm{O}_{2}$ and $\mathrm{H}_{3} \mathrm{PO}_{4}$, which involves a dissolution and re-precipitation process.

During the modified HTP process, Ti particles are dissolved in an acid solution with $\mathrm{H}_{2} \mathrm{O}_{2}$ acting as an oxidizer facilitating the $\mathrm{Ti}$ oxide generation. $\mathrm{Ti}^{4+}$ species were produced first under the presence of $\mathrm{H}_{2} \mathrm{O}_{2}$ (Eq. 1 and 2.). ${ }^{36}$

$$
\begin{array}{ll}
\mathrm{H}_{2} \mathrm{O}_{2}+2 \mathrm{H}^{+}+2 \mathrm{e}^{-} \rightarrow 2 \mathrm{H}_{2} \mathrm{O} & \text { Eq.1 } \\
\mathrm{Ti}+2 \mathrm{H}_{2} \mathrm{O}_{2}+4 \mathrm{H}^{+} \rightarrow \mathrm{Ti}^{4+}+4 \mathrm{e}^{-} & \text {Eq. } 2
\end{array}
$$

The product can further reacts with $\mathrm{H}_{2} \mathrm{O}_{2}$ to form $\mathrm{Ti}\left(\mathrm{O}_{2}\right)(\mathrm{OH})_{\mathrm{n}-2}{ }^{(4-\mathrm{n})+}(\mathrm{pH}<1)$ or $\mathrm{Ti}_{2} \mathrm{O}_{5}(\mathrm{OH})_{\mathrm{x}}{ }^{2-\mathrm{x}}(\mathrm{pH}>1, \mathrm{x}=1-6) .^{38}$ The oxidized substrate then reacts with vapor containing phosphate or hydrogen phosphate ions, leading to the deposition of 
amorphous or low-crystallinity Ti phosphate. More specifically, the dissolved Ti-based ions organise into clusters with phosphate ions, resulting in Ti-P crystal nulei followed by coarsening via the classical and/or non-classical pathways. ${ }^{37}$ For P-C-Ti, the $\pi$-TiP: $\mathrm{Ti}_{2} \mathrm{O}\left(\mathrm{PO}_{4}\right)_{2} \cdot 2 \mathrm{H}_{2} \mathrm{O}$ sheet-like crystallite radially arranged into a rosette-like clumps. Further increase the $\mathrm{H}_{3} \mathrm{PO}_{4}$, the morphology of $\pi$-TiP crystallites changed to microbundles consisting of nanobelts (P-R-Ti). High crystallinity Ti phosphate (the most stable phase under certain synthetic conditions) then grows from the surface of the dense phase forming a nanostructured $\mathrm{Ti}$ phosphate thin film with a crystal structure and morphology specific to the synthetic conditions. ${ }^{39,40}$

We used varied $\mathrm{H}_{3} \mathrm{PO}_{4} / \mathrm{H}_{2} \mathrm{O}_{2}$ concentration under optimized pressure and controlled temperature $\left(0.15 \mathrm{MPa}, 120^{\circ} \mathrm{C}\right)$ conditions to achieve tailored coatings morphology/composition. The final 3D hierarchical hybrid coatings consist of a network of interconnected spatial elements at various angles.

SEM images in Figure 1 reveal the details of different surface morphologies obtained under different HTP treatment conditions. It can be seen that the cp-Ti control sample has a relatively smooth surface with shallow pits. In contrast, the P-C-Ti surface features hemispheric rosette-like "clumps" (20-40 $\mu \mathrm{m}$ in diameter) and each "clump" consists of numerous "petals" (Figure 2C), growing radially outwards. P-G-Ti on the other hand, has a grass-like structure where bundles of short fibres were arranged randomly, leading to a porous structure. For P-R-Ti, the surface is predominantly covered by randomly aligned porous cylindrical rod structures $(7-10 \mu \mathrm{m}$ height, $5-8 \mu \mathrm{m}$ diameter). The resulting surfaces not only feature 3D structures with microscale open pores $(\sim 10 \mu \mathrm{m})$, but also spatial structures at the nanoscale (Figure $2 \mathrm{C}$ ). 


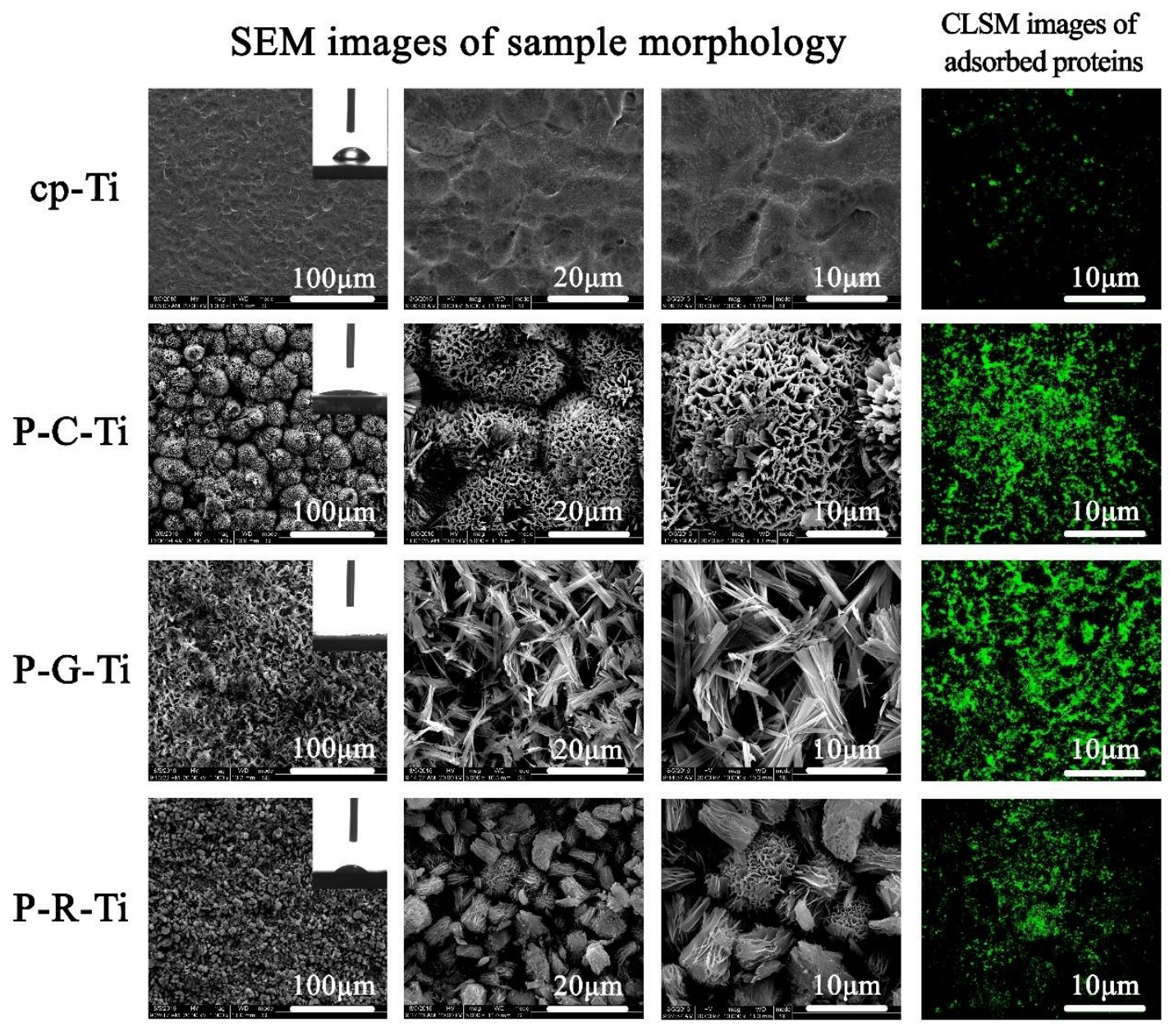

Figure 1. Left: SEM imagines showing surface morphology of different sample surfaces at different magnifications and the associated contact angle measurements (inset).

Right: Confocal laser scanning microscope (CLSM) images showing protein adsorption on each sample surface.

Surface wettability of biomaterials plays an important role in protein adsorption, which in turn has a marked impact on the adhesion and proliferation of cells. ${ }^{41}$ The wettability of all sample surfaces was shown in Figure 1 insets and the associated contact angle (CA) values were listed in Table S2. The CA measured for cp-Ti, P-C-Ti, P-G-Ti and P-R-Ti surfaces are $79 \pm 5.3^{\circ}, 13 \pm 4.9^{\circ}, 7 \pm 2.6^{\circ}$ and $26 \pm 2.1^{\circ}(p<0.05)$, respectively. The variation in $\mathrm{CA}$ for different surfaces may be attributed to the combined effect of surface chemistry and morphology. The low CA measured for P-GTi surface indicates its exceptional wettability, which may favor the protein adhesion. ${ }^{42}$ 
Subsequent protein adsorption study (see Figure 1 CLSM) confirmed that the P-G-Ti surface has the strongest cell adhesion capability (Figure S1).

Figure 2A shows the XRD patterns of all samples. While cp-Ti surface only exhibits typical Ti characteristic peaks, new diffraction peaks have been identified for surface with hybrid coatings. For instance, $\mathrm{Ti}_{2} \mathrm{O}\left(\mathrm{PO}_{4}\right)_{2} \bullet 2 \mathrm{H}_{2} \mathrm{O}$ peaks were seen in P-C-Ti, $\mathrm{Ti}\left(\mathrm{HPO}_{4}\right)_{2} \cdot 0.5 \mathrm{H}_{2} \mathrm{O}$ and $\mathrm{Ti}_{3} \mathrm{O}_{5}$ were found in $\mathrm{P}-\mathrm{G}-\mathrm{Ti}$, and peaks corresponding to $\mathrm{Ti}_{2} \mathrm{O}\left(\mathrm{PO}_{4}\right)_{2} \cdot 2 \mathrm{H}_{2} \mathrm{O}$ and $\mathrm{Ti}_{2} \mathrm{O}_{3}$ were seen for P-R-Ti. The strong intensity of the Ti phosphates characteristic peaks seen for all modified implant surfaces suggests that the Ti phosphates are highly crystalline in nature. Along with the morphological change, a perceivable decrease in intensity of the (002) peak at $2 \theta: 12.257^{\circ}$ and (012) peak at $2 \theta$ : $14.715^{\circ}$ is observed for P-C-Ti as compared to the (022) peak at $2 \theta: 20.344^{\circ}$ in P-R-Ti (Figure 2A). This indicates that the relative crystal growth rate along the $\mathrm{c}$ axis for $\pi$ TiP became slower with increasing $\mathrm{H}_{3} \mathrm{PO}_{4}$. For P-G-Ti, due to the lower concentration of $\mathrm{H}_{3} \mathrm{PO}_{4}$ and higher concentration of $\mathrm{H}_{2} \mathrm{O}_{2}$ used, the dissolved $\mathrm{Ti}^{4+}$ reacts with more abundant $\mathrm{H}_{2} \mathrm{O}_{2}$ to form greater amount of stable $\mathrm{Ti}_{2} \mathrm{O}_{3}$ and $\mathrm{TiO}_{2}$ further reacts to form Ti3O $5 .{ }^{43}$ The further interaction between $\mathrm{Ti}_{3} \mathrm{O}_{5}$ and phosphate or hydrogen phosphate ions has led to the formation of P-G-Ti which mainly consists of $\mathrm{Ti}\left(\mathrm{HPO}_{4}\right) \cdot 0.5 \mathrm{H}_{2} \mathrm{O}$ $/ \mathrm{Ti}_{3} \mathrm{O}_{5}$ compound. ${ }^{36}$

Figure 2B shows the XPS survey spectra and high-resolution spectrum of the implant surfaces. The $\mathrm{P}_{2 p}$ peaks at $133.4 \mathrm{eV}$ correspond to the binding energy of $\mathrm{P}^{\text {in }} \mathrm{PO}_{3}{ }^{4-}$ for P-C-Ti, P-G-Ti and P-G-Ti, this suggests that phosphorus has been successfully incorporated into the implant surface. To the best of our knowledge, there has been little research looked into micro/nanoscale hierarchical crystalline Ti phosphates and their effects on implant osseointegration. 


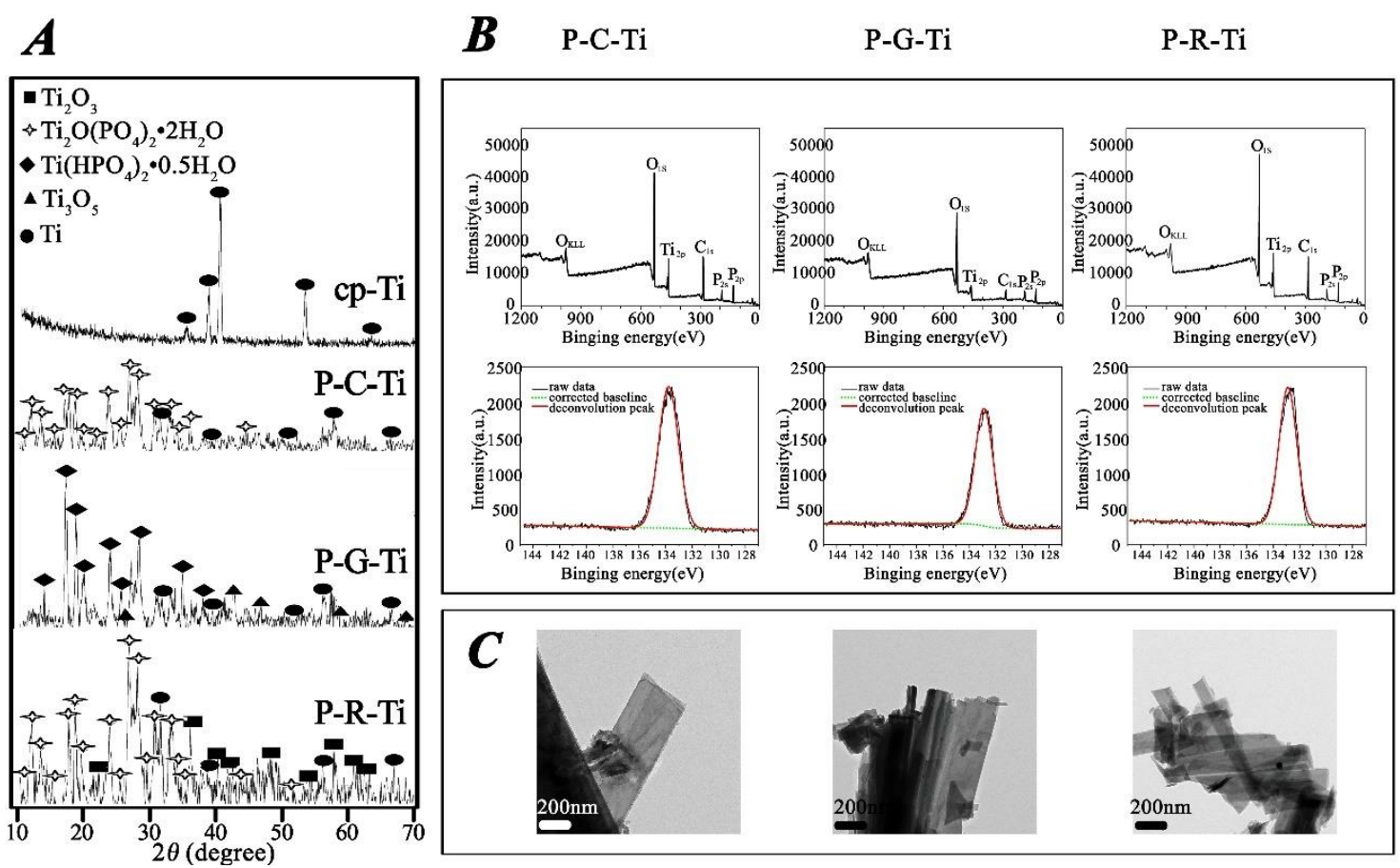

Figure 2. (A) The XRD patterns of different coatings. (B) XPS analysis showing surface binding energy of different coatings and (C) TEM images of P-C-Ti, P-G-Ti and P-R-Ti, respectively.

\section{In vitro cell behavior}

\section{Cell proliferation}

The cell response, particular that of BMSCs is very sensitive to the surface topography of biomaterials. ${ }^{44,45}$ Cell proliferation cultured on the implants can be found in Figure 3.3 (4,5-dimethylthiazol-2-yl)-2,5-diphenyl tetrazolium bromide assay (MTT, M-2128, Sigma) assay (Figure 3A) suggests that the cell viability of the three modified implants increased gradually on daily basis as compared to $\mathrm{cp}-\mathrm{Ti}$ ( $p<0.05$, apart from day 1). In addition, there was no statistical difference in the cell viability among the modified surfaces $(p>0.05)$. The cell cycle progression was further examined by flow cytometry (FCM) to confirm the MTT results. Day 3 was selected because the difference of cell expansion rate emerged at this point. The results (Figure $3 \mathrm{~B}$ and Figure S2) showed that despite the significantly different surface morphology, all the modified implant surfaces exhibited a similar accumulation of cells in the $\mathrm{S}$ phase $(p<$ 

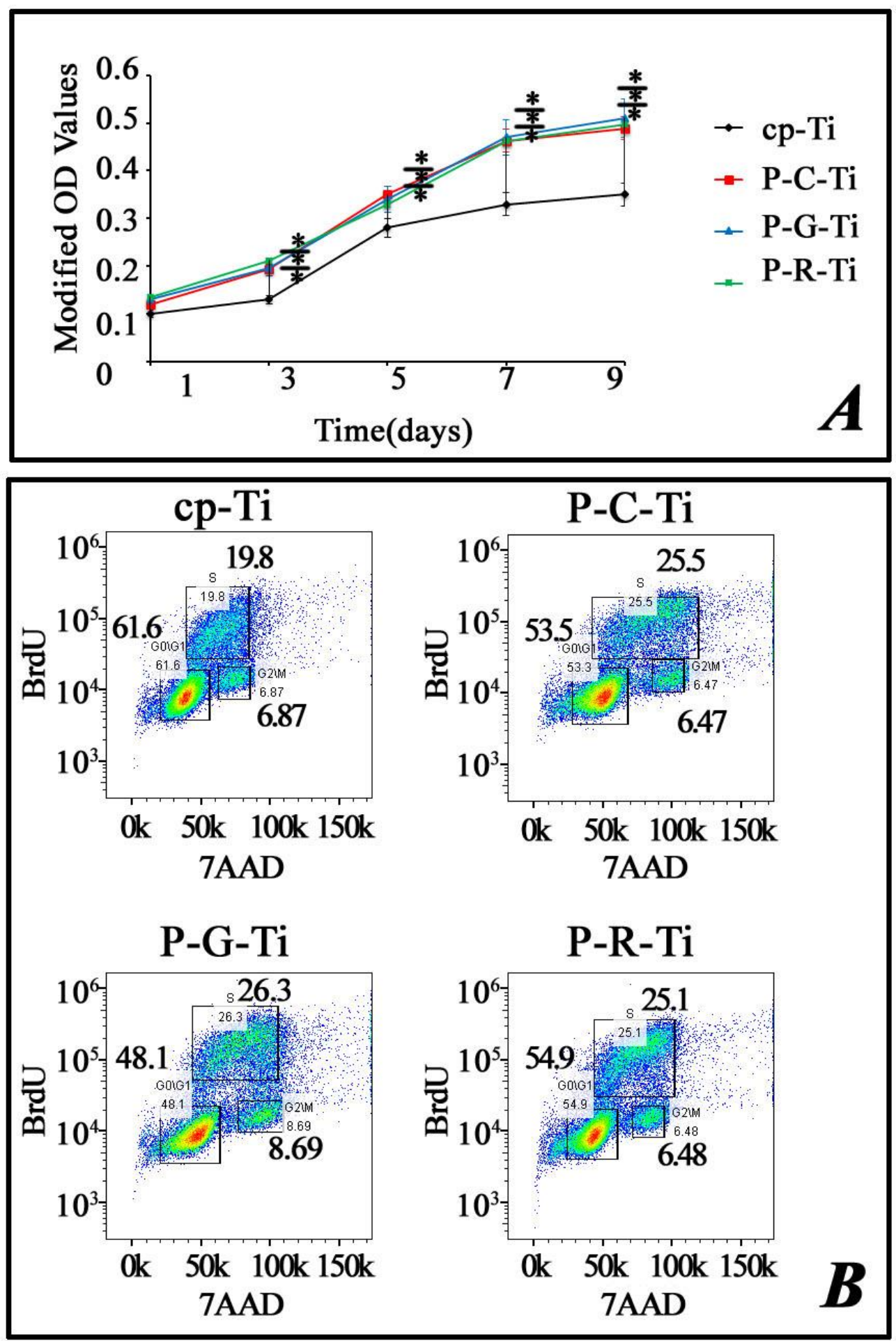

Figure 3. Proliferation assay of BMSCs cultured on different samples. (A) Viability kinetic calculated 1-9 days after cell seeding. Significant improvement was observed in all three modified samples as compared to cp-Ti; (B) FCM analysis for cell proliferation cycle. A significant increase was observed in $\mathrm{S}$ phase in the modified samples as 
compared to cp-Ti using 5'-bromo-2'-deoxyuridine (BrdU) and 7AAD stain. ${ }^{*} p<0.05$ vs cp-Ti.

Cell adhesion
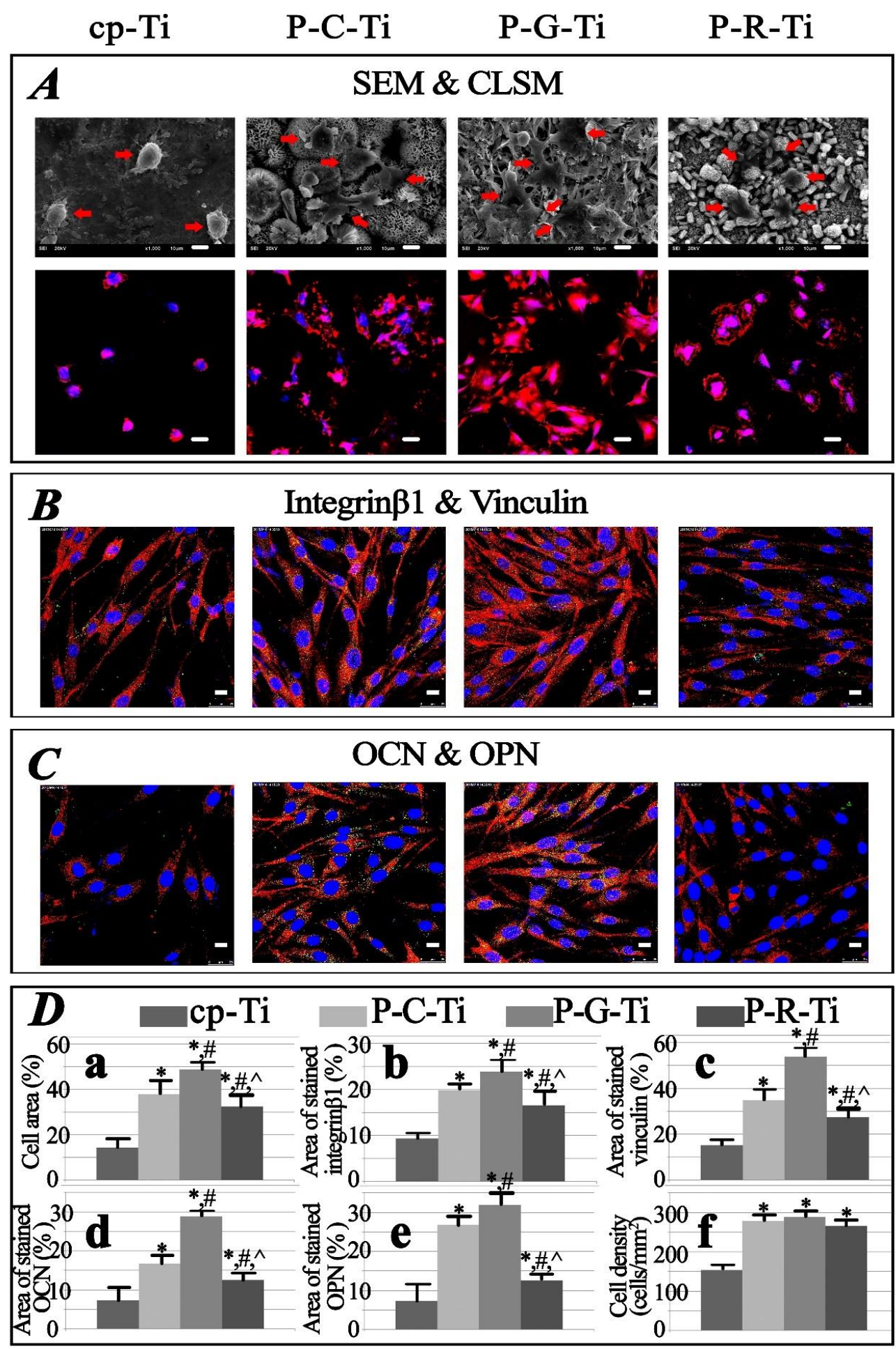

Figure 4. (A) The BMSCs morphology of initial $2 \mathrm{~h}$ incubation in each group 
investigated by SEM and CLSM; (B) The integrin $\beta 1$ and vinculin expressions of BMSCs after 48h culture in each group investigated by CLSM; (C) The OCN and OPN expression of BMCSs in each group investigated by CLSM; (D) The BMSCs adhesion area, initial adhesion proteins stained area (integrin $\beta 1$ and vinculin), osteoblastic differentiation protein stained area (OCN and OPN) and cell density in each group. Bar $=10 \mu \mathrm{m} ;{ }^{*} p<0.05$ vs cp-Ti, \#p<0.05 vs P-C-Ti, ${ }^{\wedge} p<0.05$ vs P-G-Ti.

Degree of BMSCs adhesion on different implant surfaces after $2 \mathrm{~h}$ incubation was shown in the SEM and CLSM images in Figure 4A. For the control group (cp-Ti), globular cells with limited spreading were observed in spite of the abundant filopodia found on the cell leading edge. In contrast, BMSCs on the three modified samples exhibited much better spreading featuring triangular, ellipsoidal or polygonal morphologies on P-C-Ti, P-G-Ti and P-R-Ti, respectively, accompanied by the more clearly organized cytoskeletons as confirmed by the CLSM images in Figure 4A. Apparently, cells anchored to the P-G-Ti surface demonstrated more visible interconnected lamellipodia, which is consistent with the distinctly higher F-actin expression (Figure 4Da). Likewise, in testing with the expression of both integrin $\beta 1$ and vinculin, the three modified groups manifested more abundant expression for both proteins in BMSCs compared to the cp-Ti control after $48 \mathrm{~h}$ culturing, see Figure 4B and Figure S3. A stronger fluorescent intensity is seen for fluorescence-stained cells on P-G-Ti (Figure 4A CLSM images). This, in addition to the subsequent quantitative analysis (Figure 4Db, and 4Dc), suggests that P-G-Ti favors better protein expression and stronger cell adherence $(p<0.01)$.

The trend seen for the cell adhesion is consistent to the wettability results shown in Figure 1, i.e., $\mathrm{P}-\mathrm{G}-\mathrm{Ti}>\mathrm{P}-\mathrm{C}-\mathrm{Ti}>\mathrm{P}-\mathrm{R}-\mathrm{Ti}>\mathrm{cp}-\mathrm{Ti}$, and this confirms that the genesis and development of cell adherens junction are directly influenced by surface morphology and wettability. ${ }^{46,47}$ Based on these results, Western Blot assay was applied to detect the status of the initial cell adhesion after $48 \mathrm{~h}$ seeding on the four sample groups, and the results has been shown in Figure 5. Again, stronger expression of both integrin $\beta 1$ and vinculin protein were found on modified Ti implant with P-G-Ti showing the 
strongest signal. Further mRNA expression analysis obtained from the qRT-PCR tests also indicates P-G-Ti gives the strongest expression amongst all samples, see Figure 6.

\section{Cell differentiation}

Cell differentiation is another important index to evaluate the material biocompatibility. The relative ALP activity of cells cultured on the modified samples was significantly greater than that of the cp-Ti sample ( $p<0.05)$; and the BMSCs on PG-Ti showed the highest value $(p<0.05)$ at each time point, see Figure S4. Subsequently, increased expression of osteocalcin (OCN) and osteopontin (OPN) were observed for all modified samples, see Figure 4C and Figure S5. Similar to the ALP activity assay, the brightest fluorescence-stained cells were again observed on the P-G-Ti surface, and the results is further supported by the quantitative assay (Figure 4Dd and 4De) which showed the progressively enhanced cell differentiation on the P-G-Ti surface. Additionally, the protein expression level of osteogenic factors of BMSCs on different sample surfaces has been determined. The promotion of runt-related transcription factor 2 (Runx-2) and OPN protein expression follows the trend $\mathrm{P}-\mathrm{G}-\mathrm{Ti}>\mathrm{P}-\mathrm{C}-\mathrm{Ti}>\mathrm{P}-\mathrm{R}-\mathrm{Ti}>$ cp-Ti $(p<0.05)$, as is shown in Figure 5.

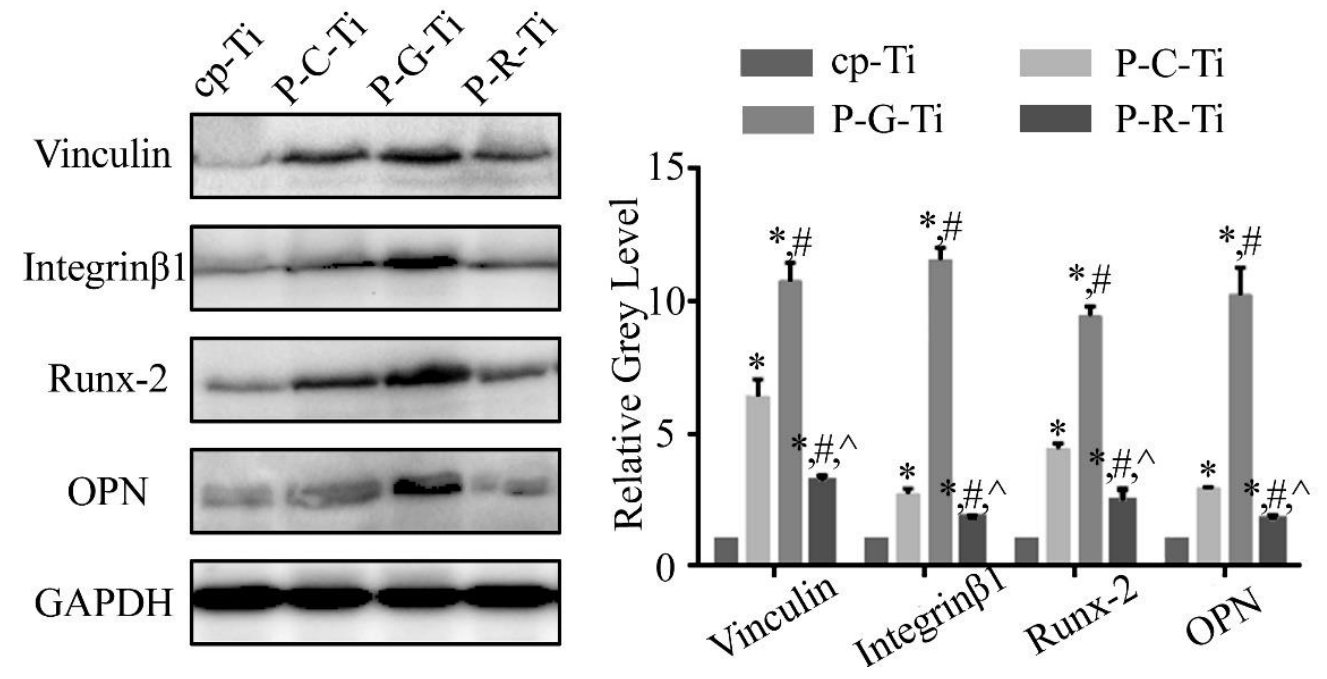

Figure 5. The western blot assay on integrin $\beta 1$, vinculin, Runx-2 and OPN for detecting initial cell adhesion and osteoblastic differentiation. ${ }^{*} p<0.05$ vs cp-Ti, $\# p<0.05$ vs $\mathrm{P}-\mathrm{C}-\mathrm{Ti}, \wedge p<0.05$ vs P-G-Ti. 
The differentiation of adherent mesenchymal stem cells along the osteoblast lineage is key to the implant osseointegration ${ }^{48}$ and the process can be influenced by the implant material phase composition and chemistry. ${ }^{49}$ It is accepted that BMSCs differentiation can be promoted by phosphorous modified Ti. ${ }^{50,51}$ In particular, the presence of crystalline phosphate favors BMSCs differentiation and bone regeneration as compared to the phosphate in amorphous state. ${ }^{52,53}$ However, very few studies have compared the BMSCs differentiation on surfaces composed of Ti, Ti oxides and Ti phosphate so far. The surface topography can also influence the BMSCs osteoblastogenesis, as the related local signaling of implant-adherent cell activation can control the osteoclastogenesis and bone accrual around endosseous implants. ${ }^{54}$ The mRNA expression of Col-1 and Runx-2 (early marker of osteoblastic differentiation) and OPN and OCN (late-stage markers) of BMSCs cultured on the different samples were assessed and the results were provided in Figure 6 (c, d, e, f). At any point in time, Col1 and Runx-2 expression levels were significantly up-regulated in the modified samples when compared with the cp-Ti control. Among all the modified samples, P-G-Ti shows the strongest osteogenesis enhancement, in line with the earlier results of the ALP assay, CLSM observation, and the western blot testing. On the other hand, BMSCs seeding on P-G-Ti has the highest expression level $(p<0.05)$ for OPN and OCN mRNA expression (Figure 6 (e) and (f)), while P-C-Ti and P-R-Ti have similar performance at $24 \mathrm{~h}$. At $48 \mathrm{~h}, \mathrm{P}-\mathrm{C}-\mathrm{Ti}$ exhibited much stronger promotion, which might be because the cell mineralization for P-C-Ti and P-R-Ti group only started at a later stage. 


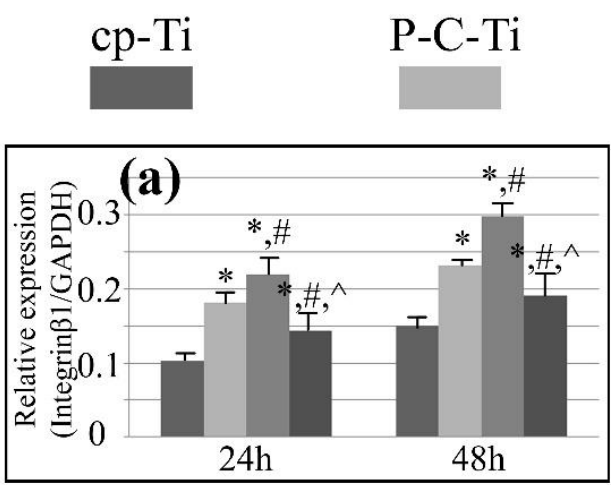

\section{P-G-Ti}

P-R-Ti
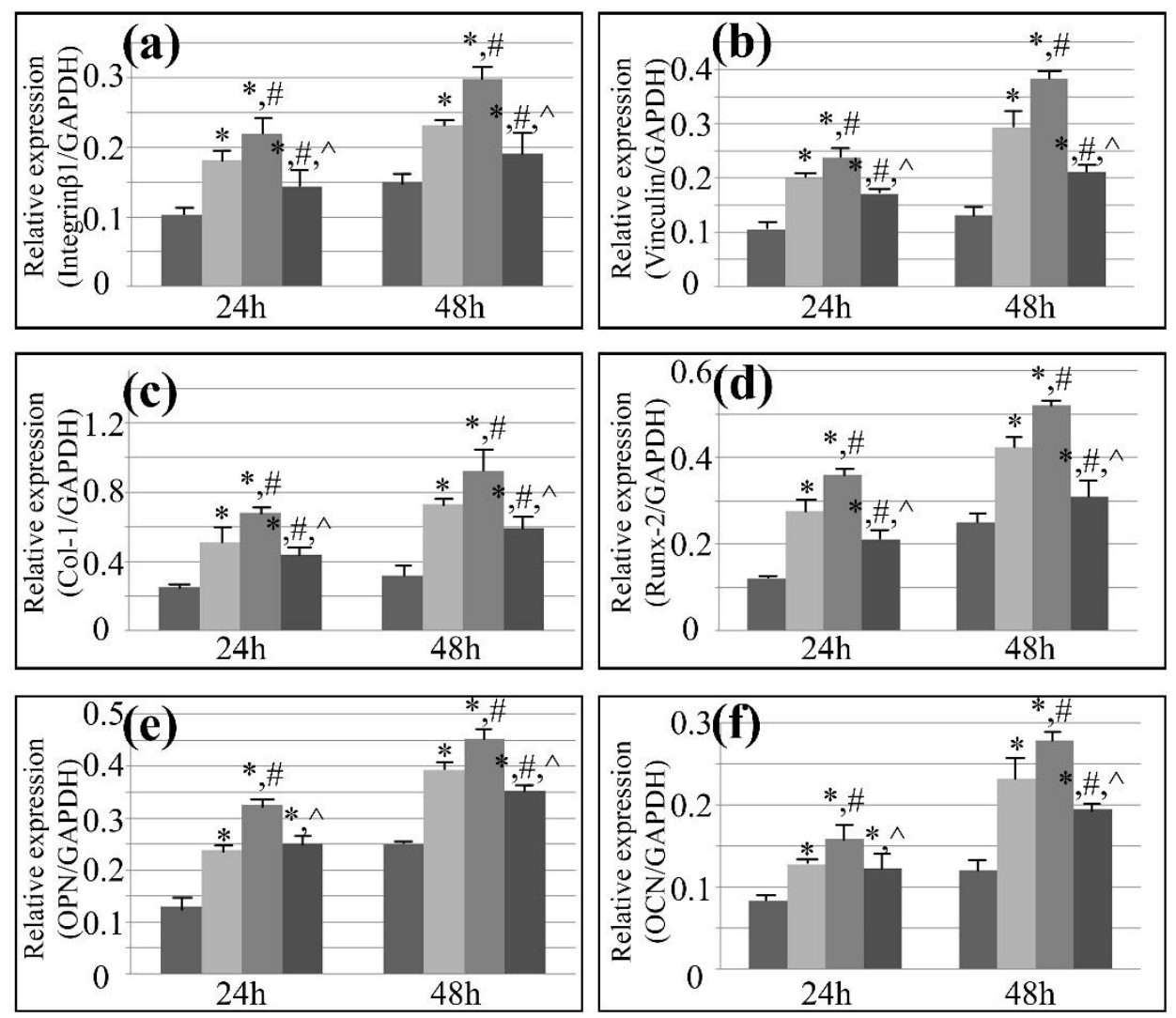

Figure 6. mRNA expression levels of integrin $\beta 1$, vinculin, Col-1, Runx-2, OPN and OCN, detected by qRT-PCR. ${ }^{*} p<0.05$ vs cp-Ti, \#p $<0.05$ vs P-C-Ti, ${ }^{\wedge} p<0.05$ vs PG-Ti.

\section{In vivo animal study}

12 weeks after the surgery, healing has been achieved in all four groups and all the Ti implants remained well-positioned inside the proximal condyle. Figure 7A shows the effects of modified implant surfaces on osseointegration and reveals the difference between different coatings. Combined with results shown in Figure 7B, it can be seen that all modified implants have markedly increased BV/TV $(p<0.05), \% \mathrm{OI}(p<0.05)$, Tb.N $(p<0.05)$ and decreased Tb.sp $(p<0.05)$. The images showing undecalcified sections with implant and the corresponding histomorphometry (Figure 8) confirm the same results that the implants modified with hybrid coatings have significantly boosted histomorphometrical parameters and that P-G-Ti surface demonstrated the most 
significant bone healing effects.

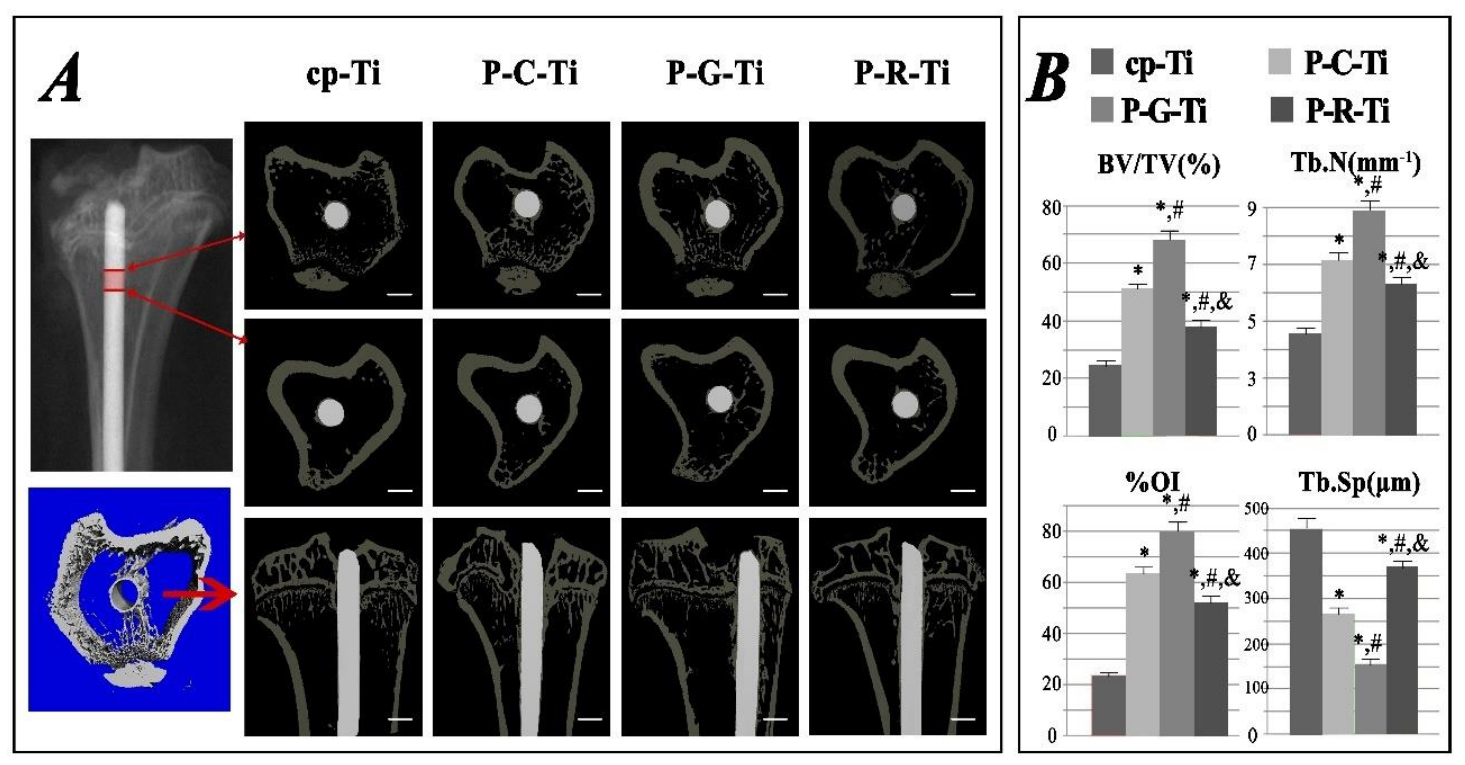

Figure 7. (A) Micro-CT imagines showing the volume of interest (VOI) in transverse and coronal planes; (B) Qualitative analysis of osseointegration 12 weeks after surgery; Bar $=1 \mathrm{~mm},{ }^{*} p<0.05$ vs cp-Ti, \#p $<0.05$ vs P-C-Ti, ${ }^{\wedge} p<0.05$ vs P-G-Ti; Abbreviation: $\mathrm{BV}$, bone volume; TV, total volume; OI, osseointegration; Tb.N, trabecular number; Tb.Sp, trabecular separation.

Results of the biomechanical tests were summarized in Figure 9A. After a 12-week period of peri-implant new bone formation, implants with P-G-Ti coating shows the greatest mechanical stability among all modified implants $(p<0.05)$. The ultimate shear strength of P-G-Ti sample is over $20 \mathrm{~N} / \mathrm{mm}^{2}$, double that of the cp-Ti sample, and the maximum pull-out force of $\mathrm{P}-\mathrm{G}-\mathrm{Ti}$ is $\sim 200 \mathrm{~N}$, four times greater than that of the cp-Ti. Figure 9B showed the typical SEM morphology of the extracted implants from the rats' tibia after the biomechanical tests. In contrast to the cp-Ti control, modified implants are covered with greater amount of bone tissue. The greatest amount of dense and thick trabeculae was found on P-G-Ti modified implant, suggesting the best bone accumulation and most effective interfacial bonding with the surrounding tissue.

Both in vitro and in vivo studies have shown consistent results that P-G-Ti 
demonstrated the best performance in terms of cell proliferation, adhesion, and differentiation and in boosting the implant osseointegration. This may be due to the combined effects of the implant surface chemistry ( $\mathrm{Ti}$ oxide incorporating crystalline Ti-P), the hierarchical micro/nano- scale surface morphology and the resulting surface superhydrophilicity. In addition, the presence of microscale interconnected pores within the coating provides a route for blood circulation and nutritional supply as is seen in cancellous bone. It also provides mechanical interlocking after the bone re-growth, contributing to the enhanced biomechanical stability. ${ }^{55}$ The "grass-like" fibres could, to certain extent, promote the cell adherence. ${ }^{56}$ Recent studies also confirmed that the hierarchical micro/nanoscale structure could activate the local immune response quickly, stimulate the cell transmembrane protein adhering and early adhesion of cells, ${ }^{57,58}$ and promote deposition of HA and proliferation of osteoblasts. ${ }^{59}$
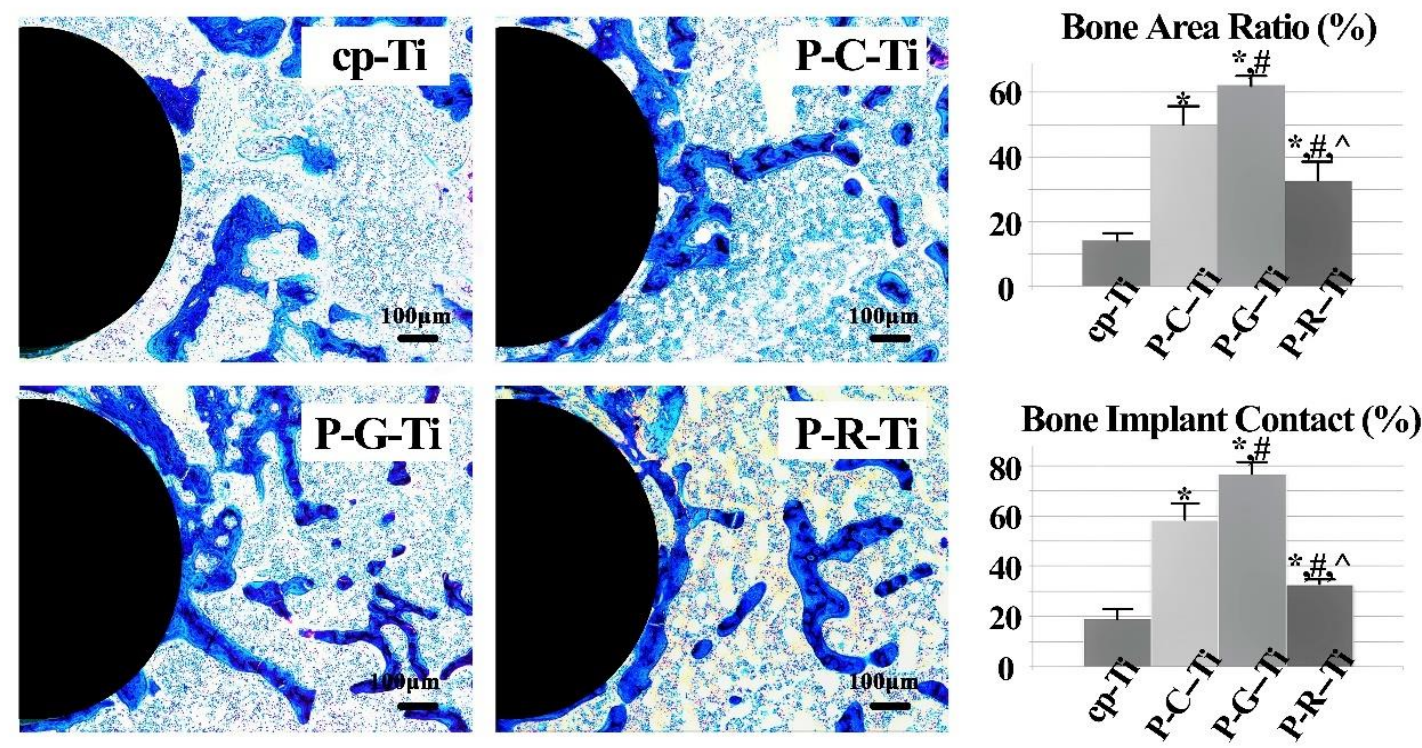

Figure 8. left: Undecalcified sections of implant approximately $2 \mathrm{~mm}$ below the epiphyseal plate; Right: quantitative evaluation results of each group 12 weeks postsurgery.

${ }^{*} p<0.05$ vs cp-Ti, \#p $<0.05$ vs $\mathrm{P}-\mathrm{C}-\mathrm{Ti}, \wedge p<0.05$ vs $\mathrm{P}-\mathrm{G}-\mathrm{Ti}$. 

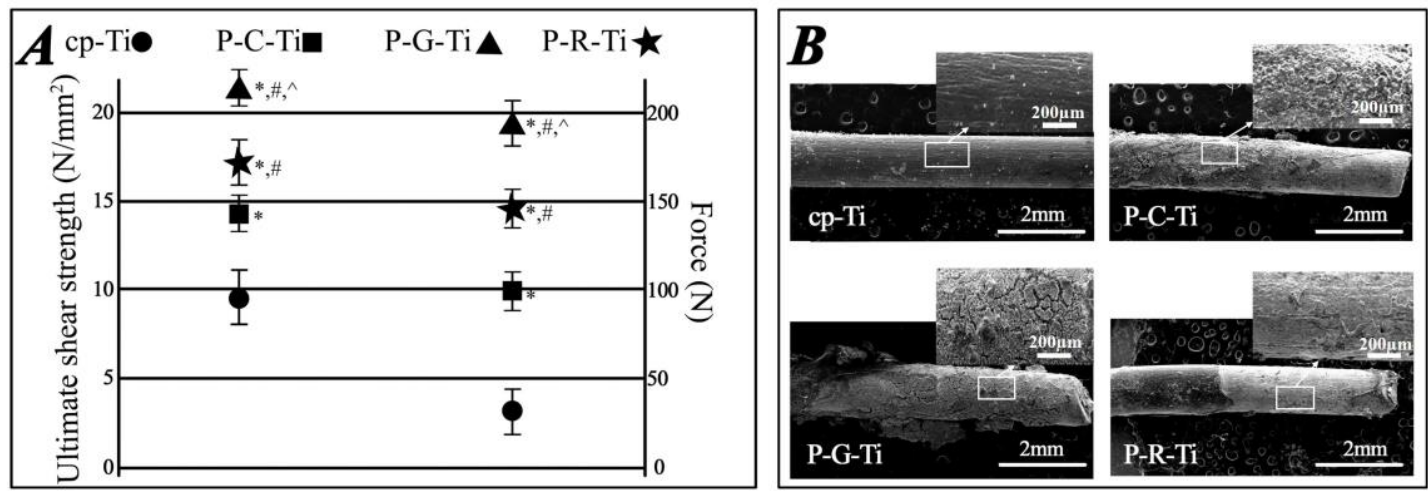

Figure 9. (A) Biomechanical testing results on ultimate shear strength and maximum push-out force 12 weeks post-surgery; (B) SEM morphology of the extracted implants 12 weeks post-surgery, insets: high resolution SEM morphology. ${ }^{*} p<0.05$ vs cp-Ti, $\# p<0.05$ vs $\mathrm{P}-\mathrm{C}-\mathrm{Ti}, \wedge p<0.05$ vs $\mathrm{P}-\mathrm{G}-\mathrm{Ti}$.

\section{Conclusions}

In the present study, hierarchical micro/nano- scaled hybrid coatings consisting of $\mathrm{Ti}$ dioxide and crystalline Ti phosphate have been created for Ti implants to enhance their osseointegration performance. Through manipulating HPT treatment conditions, hybrid coatings with tailored surface chemistry and morphology can be obtained for optimized osseointegration results. More particularly, hybrid coating featuring micro/nano-scale grass-like morphology and consisting of $\mathrm{Ti}\left(\mathrm{HPO}_{4}\right)_{2} \cdot 0.5 \mathrm{H}_{2} \mathrm{O}$ and $\mathrm{Ti}_{3} \mathrm{O}_{5}$ demonstrated the best performance both in vitro and in vivo. The results suggest that the surface chemistry and topography of the hybrid coatings produced in this study has a strong influence on the cell behaviors, such as proliferation, adhesion and differentiation, which subsequently affect the implant osseointegration and their implant biomechanical stability. The promising results seen in this study confirm our coating fabrication protocol holds great promise for improving the Ti-based implant performance and hence provide strong confidence for such hybrid coatings to be used in future practical orthopedic and dental applications.

\section{Materials and methods}

\section{Materials}


Ti plate (99.99\% purity, Baoji Ti Industry Co. Ltd., China) was machined into $\Phi 5 \mathrm{~mm} \times 1 \mathrm{~mm}$ discs (for cell experiment) and $\Phi 1 \mathrm{~mm} \times 10 \mathrm{~mm}$ rods (for animal experiment). All Ti samples were polished to mirror finish using 800, 1200, 2000 grit $\mathrm{SiC}$ sandpapers, respectively, followed by ultrasonic cleaning in acetone, ethanol and distilled water, respectively. The samples were then subjected to hydrothermal reaction in a mixture of aqueous phosphoric acid $\left(\mathrm{H}_{3} \mathrm{PO}_{4}\right.$, Kelong, Chengdu, China) and hydrogen peroxide $\left(\mathrm{H}_{2} \mathrm{O}_{2}\right.$, Kelong, Chengdu, China) in a Teflon-lined autoclave under $0.15 \mathrm{MPa}$ pressure at $120^{\circ} \mathrm{C}$ for $24 \mathrm{~h}$. The detailed reaction conditions can be found in Table 1.

Table 1. Hydrothermal reaction conditions used in this study

\begin{tabular}{|l|l|l|l|l|l|}
\hline Reactants & Nil & $\begin{array}{l}5 \mathrm{wt} \% \mathrm{H}_{3} \mathrm{PO}_{4} 8 \mathrm{wt} \% \\
\mathrm{H}_{2} \mathrm{O}_{2}\end{array}$ & $\begin{array}{l}2 \text { wt } \% \mathrm{H}_{3} \mathrm{PO}_{4} \quad 14 \\
\mathrm{wt} \% \mathrm{H}_{2} \mathrm{O}_{2}\end{array}$ & $\begin{array}{l}9 \mathrm{wt} \% \mathrm{H}_{3} \mathrm{PO}_{4} \\
7 \mathrm{wt} \% \mathrm{H}_{2} \mathrm{O}_{2}\end{array}$ \\
\hline $\begin{array}{l}\text { Hydrothermal reaction } \\
\text { conditions }\end{array}$ & Nil & 0.15MPa pressure, $120^{\circ} \mathrm{C}, 24 \mathrm{~h}$ \\
\hline Sample name & $\begin{array}{l}\text { Pure polished } \\
\text { Ti }\end{array}$ & $\begin{array}{l}\text { micro/nano-clump } \\
\mathrm{Ti}\end{array}$ & Micro/nano-grass Ti & $\begin{array}{l}\text { Micro/nano- rod } \\
\mathrm{Ti}\end{array}$ \\
\hline Acronym & $\mathrm{Cp}-\mathrm{Ti}$ & $\mathrm{P}-\mathrm{C}-\mathrm{Ti}$ & P-G-Ti & P-R-Ti \\
\hline
\end{tabular}

\section{Surface characterization}

The surface morphologies of all samples were observed using an Inspect F50 field emission scanning electron microscope (SEM, FEI, Eindhoven, Netherlands). More detailed coating microstructure was further analyzed using a transmission electron microscope (TEM, Tencnai G2 F20, FEI). The surface elemental composition was analyzed by X-ray photoelectron spectroscope (XPS, VG Scientific, ESCALAB 250, Sussex, UK), with $\mathrm{Al} \mathrm{K \alpha}(\mathrm{h} v=1486.6 \mathrm{eV})$ and the surface crystallinity of all samples were confirmed by an X-ray diffractometer (XRD, RINT-2000, Rigaku, Japan). The wettability and surface free energy of the coatings were analyzed using a contact angle goniometer (TL101, Biolin Scientific AB). The static contact angle was measured at 5 random locations on each sample, and the average value was taken. 


\section{Protein adsorption assay}

All samples were sterilized under UV radiation for $1 \mathrm{~h}$ before being transferred to a medium (a-MEM, Gibco) containing 10\% Fluorescein isothiocyanate (FITC)conjugated serum (FCS, Gibco) and immersed under $37^{\circ} \mathrm{C}$ for $2 \mathrm{~h}$. The samples were then washed thoroughly using phosphate-buffered saline solution (PBS). The adsorbed proteins were analyzed using a confocal laser scanning microscope (CLSM, LSM700, Carl Zeiss, Oberkochen, Germany).

\section{In vitro studies}

\section{Isolation and culture of bone marrow stromal cells}

Cell isolation and culture were conducted following the standards established by the Animal Research Committee of the State Key Laboratory of Oral Diseases and West

China School of Stomatology, Sichuan University (Approval number: SKLODLL2013A118). Briefly, bone marrow stromal cells (BMSCs) were harvested and extracted from the femurs of 4-week-old male Sprague-Dawley rats (Animal Research Center, Sichuan University, China) and cells at passage 2-4 were used for the cell experiment in this study. ${ }^{51}$

\section{Cell proliferation}

Sterilized Ti discs were cultured in 24-well culture plates. After 1, 3, 5, 7, and 9 days of culturing, cell viability was investigated using a 3 (4,5-dimethylthiazol-2-yl)-2,5diphenyl tetrazolium bromide assay (MTT, M-2128, Sigma). In addition, the cells cultured for 3 days were collected for flow cytometry (FCM) to further confirm cell cycle using an Accuri C6 flow cytometer (BD Biosciences). A 5'-bromo-2'deoxyuridine (BrdU) flow kit (BD Pharmingen, San Diego, CA) was used to determine the cell cycle kinetics and to measure the incorporation of BrdU into DNA of the proliferating cells. The assay was performed following the protocol recommended by the manufacturer.

\section{Cell morphology}

After 2 hours of cell incubation, the Ti samples were rinsed three times with copious 
amount of PBS to remove unattached cells. The remaining cells were fixed with $2.5 \%$ glutaraldehyde (Sigma-Aldrich). The cell morphology was analyzed using SEM and CLSM, respectively. More specifically, the cells were dehydrated in a series of ethanol solutions $(20 \%, 40 \%, 60 \%, 80 \%, 90 \%$, and $100 \%)$ and then gold sputtered for SEM analysis. After permeabilization with $0.2 \%$ Triton X-100 (Sigma-Aldrich) for 15 min, the cells were incubated with rhodamine-conjugated phalloidin for 20 min to stain cytoskeleton. Image $\mathrm{J}$ software (NIH, USA) was used to quantify the cell attachment area.

\section{ALP activity assay}

The ALP activity assay was used to detect cell differentiation on different samples. Seeded at a density of $5 \times 10^{4}$ cells/well, the cells were incubated for 1,3 , and 7 days on all the Ti samples. The culture was then fixed by $4 \%$ paraformaldehyde (SigmaAldrich) and stained with an ALP kit (BCIP/NBT, Beyotime). Optical density (OD) values for absorbance at $405 \mathrm{~nm}$ was measured to determine the ALP activity.

\section{Cell immunofluorescence staining}

Cell immunofluorescence staining, the expressions of integrin $\beta 1$, vinculin, osteocalcin (OCN) and osteopontin (OPN) on the experimental samples were detected by CLSM. After incubation with the samples for $48 \mathrm{~h}$ and $96 \mathrm{~h}$, the cells were fixed in 4\% paraformaldehyde, and permeabilized with $0.2 \%$ Triton X-100. Subsequently, 4', 6-diamidino-2-phenylindole (DAPI, company, country) and specific antibodies targeting protein of interest were added sequentially and co-incubated for $4 \mathrm{~h}$ as previously described. ${ }^{51}$ All procedure was completed in dark and all samples were observed using CLSM after thorough rinsing using PBS.

\section{Western blot assay}

The membrane was first blocked with 5\% BSA (Gibco, USA) in TTBS solution. The samples were then incubated with anti-integrin $\beta 1$, anti-vinculin, anti-Runx-2, and antiOPN primary antibody (1:500 dilution; Abcam, UK) followed by horseradish peroxidase (HRP) conjugated secondary antibody (1:3500 dilution; CST, USA) for 60 min under room temperature. The intensity of the protein bands was quantified on a Western-Light Chemiluminescent Detection System. 


\section{Quantitative real-time PCR analysis (qRT-PCR)}

Cells incubated with Ti discs for $24 \mathrm{~h}$ and $48 \mathrm{~h}$ were collected separately for qRTPCR tests. The RNA expressions were explored for the following factors: integrin $\beta 1$, vinculin, runt-related transcription factor 2 (Runx-2), collagen type I (Col-I), osteopontin (OPN) and osteocalcin (OCN). Glyceraldehyde-3P-dehydrogenase (GAPDH) was used as the internal RNA control and the primer sequences were listed in Table S1.

\section{In vivo animal study}

\section{Animal model}

40 female SD rats ( 3 months old, weight $210 \mathrm{~g} \sim 230 \mathrm{~g}$ ) were randomly assigned into four groups. Animal feeding and handling were in line with the international guidance on animal welfare and the standards of the Animal Research Committee of the State Key Laboratory of Oral Diseases and West China School of Stomatology, Sichuan University (Approval number: WCCSIRB-D-2014-407). A 1-mm hole perpendicular to the axis of bone was drilled and the implants were inserted into the medullary canal of the tibiae as shown in Figure S6. The soft tissues were then sutured and intramuscular antibiotic and analgesic injection was given to the animals for 3 days post-surgery. More details on the animal model can be found in. ${ }^{60}$

\section{Micro-CT evaluation ( $\mu-\mathrm{CT})$}

12 weeks after surgery, the tibiae with implants ( $n=10$ per group) were harvested and surveyed by a high resolution $\mu$-CT scanner system (Scanco Medical $\mu$-CT 50, Switzerland). The volume of interest (VOI) was defined as the bone section around the implant from $2 \mathrm{~mm}$ below the growth plate to distal 100 slices with a ring radius of 250 $\mu \mathrm{m}$ from the implant surface. 2D micro-CT screenshots of the transverse plane at the start of the VOI range (about $2 \mathrm{~mm}$ below the epiphyseal plate) and the end of VOI (100 slices below the VOI starting point), as well as that of the coronal plane (through the center of implant axis) were collected. The osteogenesis properties, more specifically, the bone volume per total sample volume (BV/TV), the percentage of bone-to-implant contact (\% osseointegration, \%OI), the mean trabecular number (Tb.N) and the mean trabecular separation (Tb.Sp) were calculated after reconstruction of the 
VOI.

\section{Histological analysis}

12 weeks after surgery, another set of tibiae with implants ( $n=10$ per group) were subjected to undecalcified dissections. The histological evaluation was carried out on sections approximately $1 \mathrm{~mm}$ below the growth plate using a Leica DM-RBE microscope (Leica, Germany). The bone area ratio (BA) was defined as the percentage of mature bone within the whole tissue region (a ring region extending $250 \mu \mathrm{m}$ from the implant surface). The bone-to-implant contact (BC) was defined as the percentage of the linear fraction of mineralized bone in direct contact with the implant interface based on the analysis using the NIS-Elements F2.20 image software (Media Cybernetics, USA).

\section{Biomechanical test}

Biomechanical test was performed on the $\mu$-CT scanned samples ( $n=10$ per group) to determine the ultimate shear strength and maximum push-out force. Peak torque values $\left(\mathrm{N} / \mathrm{mm}^{2}\right)$ and forces at the start of rotation $(\mathrm{N})$ were detected using a biomechanical testing equipment (BSC30, Yinbo Scientific Equipment, China) at a speed of $1 \mathrm{~mm} / \mathrm{min}$. More detailed testing method can be found elsewhere. ${ }^{60}$ Immediately after the biomechanical test, the extracted implants were treated by $2.5 \%$ glutaraldehyde, dehydrated with alcohol, freeze dried (EMS 850 critical point dryer, Electron Microscopy Science Co., Hillsboro, USA) and gold-sputtered for further SEM observation.

\section{Statistical analysis}

Data were expressed as mean and standard deviation (SD) and analyzed using SPSS 16.0 software (SPSS, USA) to determine the level of significance. One-way ANOVA followed by Bonferroni's multiple comparison was applied for the statistical analysis. Statistical significance was considered for $p<0.05$ while high significance was $p<$ 0.01 .

\section{Author Information}

Corresponding Authors 
*Tel.:+86-28-85411552. E-mail: zhangli9111@126.com (Li Zhang).

*Tel.:+86-28-61153299. E-mail: zss_1977@163.com (Songsong Zhu).

\section{Author Contributions}

$\dagger$ N. Jiang and Z. Guo contributed equally to this work.

N. Jiang, Z. Guo, L. Zhang and S. Zhu conceived ideas of this work. Z. Guo carried out all experimental work in relation to materials synthesis and characterization. N. Jiang performed all biology related work (cell and animal). All authors contributed to the analysis of data and result discussion as well as the writing of the manuscript.

\section{Acknowledgements}

This work was supported by the National natural science foundation of China (No.51673131),National Key Research and Development Program of China (2016YF A0201703/2016YFA0201700) and China Scholarship Council (201606240059).

Competing Interests: The authors declare that they have no competing interests. 


\section{Reference}

1. Economic UPDUNDo, Affairs S. World Population Ageing 2013.

2. Petropoulou, A.; Pappa, E.; Pelekanos, S. Esthetic Considerations When Replacing Missing Maxillary Incisors with Implants: A Clinical Report. J. Prosthet. Dent. 2013, 109, 140-144.

3. Markel, D. C.; Allen, M. W.; Zappa, N. M. Can An Arthroplasty Registry Help Decrease Transfusions in Primary Total Joint Replacement? A Quality Initiative. Clin. Orthop. Relat. Res.2016, 474, 126-131.

4. Meinardi, J. E.; Valstar, E. R.; Der Voort, P. V.; Kaptein, B. L.; Fiocco, M.; Nelissen, R. G. Palacos Compared to Palamed Bone Cement in Total Hip Replacement: A Randomized Controlled Trial: RSA Migration Similar at 10year Follow-up. Acta Orthop. 2016, 87, 473-478.

5. Guo, Z.; Chen, C.; Gao, Q.; Li, Y.; Zhang, L.; Fabrication of Silver-Incorporated $\mathrm{TiO}_{2}$ Nanotubes and Evaluation on Its Antibacterial Activity. Mater. Lett. 2014, $137,464-467$.

6. Viorney, C.; Chevolot, Y.; Léonard, D.; Aronsson, B.; Péchy, P.; Mathieu, H.; Descouts, P.; Grätzel, M. Surface Modification of Titanium with Phosphonic Acid To Improve Bone Bonding: Characterization by XPS and ToF-SIMS. ACS Nano. 2002. 18, 2582-2589.

7. Guo, Z.; Jiang, N.; Chen, C.; Zhu, S.; Zhang, L.; Li, Y. Surface Bioactivation Through The Nanostructured Layer on Titanium Modified by Facile HPT Treatment. Sci. Rep. 2017, 7, 4155.

8. Guo, Z.; Pan, H.; Wang, L.; Zhou, B.; Li, Y.; Zhang, L. Fabrication of pHSensitive Membrane on Ag-Loaded Titania Nanotube and Its Antibacterial Properties. Chin. J. Inorg. Chem. 2014, 6, 1299-1304.

9. Wang, W; Khoon, C. Titanium Alloys in Orthopaedics. In: Titanium AlloysAdvances in Properties Control; Sieniawski, J. and Ziaja, W., Eds.; Oxford, UK 2013; pp $17-143$. 
10. Macinnes, S. J.; Gordon, A.; Wilkinson, J. M. Risk Factors for Aseptic Loosening Following Total Hip Arthroplasty. In: Recent Advanced in Arthroplasty; Fokter, S., Eds.; Sheffield, UK 2012; chapter 14, pp 275-294.

11. Prime, M.S.; Palmer, J.; Khan, W.S. National Joint Registry for England and Wales $7^{\text {th }}$ annual report, 2011.

12. Long, M.; Rack, H. J. Titanium Alloys in Total Joint Replacement-A Materials Science Perspective. Biomaterials. 1998, 19, 1621-1639.

13. Wang, Q.; Qiao, Y.; Cheng, M.; Jiang, G.; He, G.; Chen, Y. Tantalum Implanted Entangled Porous Titanium Promotes Surface Osseointegration and Bone Ingrowth. Sci. Rep. 2016, 6,26248.

14. Shibata, Y.; Tanimoto, Y. A Review of Improved Fixation Methods for Dental Implants. Part I: Surface Optimization for Rapid Osseointegration. $J$. Prosthodont. Res. 2015, 59, 20-33.

15. Facca, S.; Lahiri, D.; Fioretti, F.; Messadeq, N.; Marinard, D.; Benkirane-Jessel, N.; Agarwal, A. In Vivo Osseointegration of Nano-Designed Composite Coatings on Titanium Implants. ACS Nano. 2011, 5, 4790-4799.

16. Zhang, M.; Cheng, H.; Gong, Z.; Zhang, J.; Liu, X.; Wang, B.; Ban, L.; Zeng, Y.; Zhu, Z. Abrication of Chitosan-18ß-Glycyrrhetinic Acid Modified Titanium Implants with Nanorod Arrays for Suppression of Osteosarcoma Growth and Improvement of Osteoblasts Activity. Adv. Funct. Mater. 2017, 27, 1703932.

17. Bedi, R. S.; Zanello, L. P.; Yan, Y. Bone implants: Osteoconductive and Osteoinductive Properties of Zeolite MFI Coatings on Titanium Alloys. Adv. Funct. Mater. 2009, 19, 3856.

18. Rubin, M. A.; Jasiuk, I.; Taylor, J.; Rubin, J.; Ganey, T.; Apkarian, R. P. TEM Analysis of The Nanostructure of Normal and Osteoporotic Human Trabecular Bone. Bone. 2003, 33,270-282.

19. Chen, X.; Wang, W.; Cheng, S.; Dong, B.; Li, Y. Mimicking Bone Nanostructure by Combining Block Copolymer Self-Assembly and 1D Crystal Nucleation. ACS Nano, 2013, 7, 8251-8257. 
20. Wu, S.; Liu, X.; Hu, T.; Chu, P. K.; Ho, J. P. Y.; Chan, Y. L.; Yeung, K. W. K.; Chu, C. L.; Hung, T. F.; Chung, C. Y.; Lu, W. W.; Cheung, K. M. C.; Luk, K. D. K. A Biomimetic Hierarchical Scaffold: Natural Growth of Nanotitanates on Three-Dimensional Microporous Ti-based Metals. Nano Lett. 2008, 8, 38033808.

21. Stevens, M. M.; George, J. H. Exploring and Engineering The Cell-Surface Interface. Science. 2005, 310, 1135-1138.

22. Knabe, C.; Howlett, C. R.; Klar, F.; Zreiqat, H. The Effect of Different Titanium and Hydroxyapatite-Coated Dental Implant Surfaces on Phenotypic Expression of Human Bone-Derived Cells. J. Biomed. Mater. Res., Part A. 2004, 71A, 98-107.

23. Ong, J. L.; Bessho, K.; Cavin, R.; Carnes, D. L. Bone Response to Radio Frequency Sputtered Calcium Phosphate Implants and Titanium Implants in Vivo. J. Biomed. Mater. 2002, 59, 184-190.

24. Yan, W. Q; Nakamura, T.; Kobayashi, M.; Kim, H. M.; Miyaji, F.; Kokubo, T. Bonding of Chemically Treated Titanium Implants to Bone. J. Biomed. Mater. Res., Part A 1997, 37, 267-275.

25. Park, J. W.; Kim, Y. J.; Jang, J. H. Enhanced Osteoblast Response to Hydrophilic Strontium and/or Phosphate Ions-incorporated Titanium Oxide Surfaces. Clin. Oral Implants Res. 2010, 21, 398-408.

26. Olivares-navarrete, R.; Hyzy, S. L.; Hutton, D. L.; Erdman, C. P.; Wieland, M.; Boyan, B. D.; Schwartz, Z. Direct and Indirect Effects of Microstructured Titanium Substrates on The Induction of Mesenchymal Stem Cell Differentiation Towards The Osteoblast Lineage. Biomaterials. 2010, 31, 2728-2735.

27. Zhao, C.; Cao, P.; Ji, W.; Han, P.; Zhang, J.; Zhang, F.; Jiang, Y.; Zhang X. Hierarchical Titanium Surface Textures Affect Osteoblastic Functions. $J$. Biomed. Mater. Res., Part A 2011, 99A, 666-675.

28. Olivares-navarrete, R.; Gittens, R. A.; Schneider, J. M.; Hyzy, S. L.; Haithcock, D. A.; Ullrich, P. F.; Schwartz, Z.; Boyan, B. D. Osteoblasts 
Exhibit A More Differentiated Phenotype and Increased Bone Morphogenetic Protein Production On Titanium Alloy Substrates Than on Poly-Ether-EtherKetone. Spine J. 2012, 12, 265-272.

29. Schwartz, Z.; Olivares-navarrete, R.; Wieland, M.; Cochran, D. L.; Boyan, B. D. Mechanisms Regulating Increased Production of Osteoprotegerin by Osteoblasts Cultured on Microstructured Titanium Surfaces. Biomaterials. 2009, 30, 3390-3396.

30. Milinkovic, I.; Rudolf, R.; Raić, K. T.; Aleksic, Z.; Lazic, V.; Todorovic, A.; Stamenkovic, D. Aspects of Titanium-Implant Surface Modification at The Micro and Nano Levels. Materials and technology. 2012, 46, 251-256.

31. Skorb, E. V.; Andreeva, D. V. Surface Nanoarchitecture for Bio-applications: Self-Regulating Intelligent Interfaces. Adv. Funct. Mater. 2013, 23, 4483-4506.

32. Yin, C.; Zhang, Y.; Cai, Q.; Li, B.; Yang, H.; Wang, H; Qi, H.; Zhou, Y.; Meng. W. Effects of The Micro-Nano Surface Yopography of Titanium Alloy on The Biological Responses of Osteoblast. J. Biomed. Mater. Res., Part A 2017, 105, 757-769.

33. Lin, L.; Wang, H.; Ni, M.; Rui, Y.; Cheng, T.; Cheng, C.; Pan, X.; Li, G.; Lin, C. Enhanced Osteointegration of Medical Titanium Implant with Surface Modifications in Micro/Nanoscale Structures. J. Orthop. Translat. 2014, 2,35.

34. Sul, Y. T. The Significance of The Surface Properties of Oxidized Titanium to The Bone Response: Special Emphasis on Potential Biochemical Bonding of Oxidized Titanium Implant. Biomaterials. 2003, 24, 3893-3907.

35. Park, J. W.; Kim, Y. J.; Jang, J. H.; Kwon, T. G.; Bae, Y. C.; Suh, J. Y. Effects of Phosphoric Acid Treatment of Titanium Surfaces on Surface Properties, Osteoblast Response and Removal of Torque Forces. Acta Biomater. 2010, 6, 1661-1670.

36. Yada, M.; Inoue, Y.; Sakamoto, A.; Torikai, T.; Watari, T. Synthesis and Controllable Wettability of Micro- and Nanostructured Titanium Phosphate Thin Films Formed on Titanium Plates. ACS Appl. Mater. Interfaces. 2014, 6, 7695. 
37. Zhu, Y.; Hasegawa, G.; Kanamori, K.; Kiyomura, T.; Kurata, H.; Hayashi, K.; Nakanishi, K. Nanostructured titanium phosphates prepared via hydrothermal reaction and their electrochemical $\mathrm{Li}$ - and $\mathrm{Na}$-ion intercalation properties. CrystEngComm. 2017, 19, 4551-4560.

38. Schwarzenbach, G.; Muehlebach, J.; Mueller, K. Peroxo Complexes of Titanium. Inorg. Chem. 1970, 9, 2381-2390.

39. Guo, Y.; Lee, N. H.; Oh, H. J.; Yoon, C. R.; Park, K. S.; Lee, H. G.; Lee, K. S.; Kim, S. J. Structure-Tunable Synthesis of Titanate Nanotube Thin Films via A Simple Hydrothermal Process. Nanotechnology. 2007, 18, 295608.

40. Yada, M.; Inoue, Y.; Uota, M.; Torikai, T.; Watari, T.; Noda, I.; Hotokebuchi T. Plate, Wire, Mesh, Microsphere, and Microtube Composed of Sodium Titanate Nanotubes on A Titanium Metal Template. Langmuir. 2007, 23, 28152823.

41. Kirchhof, K.; Groth, T. Surface modification of biomaterials to control adhesion of cells. Clin. Hemorheol. Microcirc. 2008, 39, 247-251.

42. Wei, J.; Igarashi, To.; Okumori, N.; Igarashi, Ta; Maetani, T; Liu, B; Yoshinari, M. Influence of Surface Wettability on Competitive Protein Adsorption and Initial Attachment of Osteoblasts. Biomed. Mater. 2009, 4, 045002.

43. George, L. Humphrey. The Heats of Formation of $\mathrm{TiO}, \mathrm{Ti}_{2} \mathrm{O}_{3}, \mathrm{Ti}_{3} \mathrm{O}_{5}$ and $\mathrm{TiO}_{2}$ from Combustion Calorimetry ${ }^{1}$. J.Am.Chem.Soc. 1957, 73, 1587-1590.

44. Ignotz, R. A.; Massague, J. Cell Adhesion Protein Receptors as Targets for Transforming Growth Factor- $\beta$ Action. Cell. 1987, 51, 189-197.

45. Thakral G. K.; Thakral R.; Sharma N.; Seth J.; Vashisht P. Nanosurface - The Future of Implants. J. Clin. Diag. Res. 2014, 8, 7-10.

46. Meng, W.; Takeichi, M. Adherens Junction: Molecular Architecture and Regulation. Cold Spring Harb Perspect Biol. 2009, 1, a002899.

47. Ishizaki, T.; Saito, N.; Takai O. Correlation of Cell Adhesive Behaviors on Superhydrophobic, Superhydrophilic, and Micropatterned Superhydrophobic/ 
Superhydrophilic Surfaces to Their Surface Chemistry. Langmuir. 2010, 26, 8147-8154.

48. Hu, D.; Li, K.; Xie, Y.; Pan, H.; Zhao, J.; Huang, L.; Zheng X. The Combined Effects of Nanotopography and Sr Ion for Enhanced Osteogenic Activity of Bone Marrow Mesenchymal Stem Cells (BMSCs). J. Biomater. Appl. 2017, 31, 1135-1147.

49. Li, K.; Shen, Q.; Xie, Y.; You, M.; Huang, L.; Zheng, X. Incorporation of Cerium Oxide Into Hydroxyapatite Coating Regulates Osteogenic activity of Mesenchymal Stem Cell and Macrophage Polarization. J. Biomater. Appl. 2017, 31, 1062-1076.

50. Park, J. W.; Jang, J. H.; Lee, C. S.; Hanawa, T. Osteoconductivity of Hydrophilic Microstructured Titanium Implants with Phosphate Ion Chemistry, Acta Biomater. 2009, 5,2311-2321.

51. Jiang, N.; Du, P.; Qu, W.; Li, L.; Liu, Z.; Zhu, S. The Synergistic Effect of $\mathrm{TiO}_{2}$ Nanoporous Modification and Platelet-Rich Plasma Treatment on Titanium-Implant Stability in Ovariectomized Rats. Int. J. Nanomedicine. 2016, 11, 4719-4733.

52. Chesnutt, B. M. ; Viano, A. M.; Yuan, Y.; Yang, Y.; Guda, T.; Appleford, M. R.; Ong, J. L. ; Haggard, W. O.; Bumgardner, J. D. Design and Characterization of A Novel Chitosan/Nanocrystalline Calcium Phosphate Composite Scaffold for Bone Regeneration. J. Biomed. Mater. Res., Part A. 2009, $88 A, 491-502$.

53. Gildenhaar, R.; Knabe, C.; Gomes, C.; Linow, U.; Houshmand, A.; Berger, G. Calcium Alkaline Phosphate Scaffolds for Bone Regeneration 3D-Fabricated by Additive Manufacturing. Key Engin. Mater. 2012, 493-494, 849-854.

54. Nagasawa, M.; Cooper L. F.; Ogino, Y.; Mendonca, D. ; Liang, R. ; Yang, S.; Mendonca, G.; Uoshima, K. Topography Influences Adherent Cell Regulation of Osteoclastogenesis. J. Dent. Res. 2016, 95, 319-326.

55. Wu, S.; Liu, X.; Hu, T.; Chu, P. K.; Ho, J. P. Y. ; Chan, Y. L.; Yeung, K. W. ; Chu, C. L. ; Hung, T. F.; Huo, K. F.; Chung, C. Y.; Lu, W. W.; Cheung, K. M.; 
Luk, K. D. A Biomimetic Hierarchical Scaffold: Natural Growth of Nanotitanates on Three-Dimensional Microporous Ti-based Metals. Nano Lett. 2008, 8, 3803.

56. Terranova, L.; Mallet, R.; Perrot, R.; Chappard, D. Polystyrene Scaffolds Based on Microfibers as A Bone Substitute: Development and in Vitro study. Acta Biomater. 2016, 29, 380-388.

57. Filová, E.; Supoý, T.; Sucharda, Z; Supová M; Zaloudkavá, M.; Balík, K. ; Lisá, V. ; Slouf, M.; Bacáková, L. Support for The Initial Attachment, Growth and Differentiation of MG-63 Cells: A Comparison between Nano-size Hydroxyapatite and Micro-size Hydroxyapatite in Composites. Int. J. Nanomed. 2014, 9, 3687-3706.

58. Park, J. W.; Kim, Y. J.; Jang, J. H.; Suh, J. Y.. Surface Characteristics and Primary Bone Marrow Stromal Cell Response of A Nanostructured StrontiumContaining Oxide Layer Produced on a Microrough Titanium Surface. $J$. Biomed. Mater. Res., Part A. 2012, 100A, 1477-1487.

59. Woo, K. M.; Jun, J. H.; Chen, V. J.; Seo, J ; Baek, J. H.; Ryoo, H. M.; Kim, G. S.; Somerman, M. J.; Ma, P. X. Nano-Fibrous Scaffolding Promotes Osteoblast Differentiation and Biomineralization. Biomaterials. 2007, 28, 335-343.

60. Li, Y.; Zou, S.; Wang, D.; Feng, G.; Bao, C.; Hu, J. The effect of hydrofluoric acid treatment on titanium implant osseointegration in ovariectomized rats. Biomaterials. 2010, 31, 3266-3273. 